\title{
Affordable digital innovation to reduce SARS-CoV-2 transmission among healthcare workers
}

\author{
S D Ntshalintshali, ${ }^{1,2} \mathrm{MB} \mathrm{ChB}, \mathrm{MMed}(\mathrm{Int} \mathrm{Med}), \mathrm{FCP}(\mathrm{SA}) ;$ C Mnqwazi, ${ }^{2} \mathrm{MB} \mathrm{ChB}$ \\ ${ }^{1}$ Division of Rheumatology, Department of Internal Medicine, Tygerberg Hospital and Faculty of Medicine and Health Sciences, Stellenbosch \\ University, Cape Town, South Africa \\ ${ }^{2}$ Department of Internal Medicine, Tygerberg Hospital and Faculty of Medicine and Health Sciences, Stellenbosch University, Cape Town, \\ South Africa
}

Corresponding author: S D Ntshalintshali (sipho.duncan@gmail.com)

\begin{abstract}
In the South African public healthcare sector, patient medical records are still written on paper and stored in filing rooms. There has been an attempt to move towards a paperless electronic system in many public healthcare facilities, but owing to lack of funding, this has been a challenge to achieve. During the current COVID-19 pandemic, the virus could be transmitted through the physical manipulation of patient records by various categories of staff who handle the records with or without gloves for protection. We discuss a digital option that has been partially used at Tygerberg Hospital (TBH), Cape Town, to avoid SARS-CoV-2 patient hard-copy record manipulation. It includes assignment of a QR code to every patient admitted as a person under investigation or confirmed COVID-19 case. The QR code is synced to one of the many free online medical notes smartphone applications (apps), which are password-protected with patient information privacy regulations (Trello is used at $\mathrm{TBH}$ ), for daily medical notes review and editing. Upon discharge, all notes made during the patient's hospital stay, together with the discharge summary, are printed to generate a hard copy of notes for filing to avoid violation of the current national and provincial patient records policy. Doing this means that a patient will have a virtual online file through the designated app until discharge, when a physical file will be made for storage and safekeeping. It will keep physical manipulation of patient records to the minimum, and potentially assist in reducing transmission of the SARS-CoV-2 virus among healthcare workers.
\end{abstract}

S Afr Med J 2020;110(7):605-606. https://doi.org/10.7196/SAMJ.2020.v110i7.14879

Patient record files in public hospitals are handled by multiple members of staff and are therefore capable of transmitting the SARSCov-2 virus among healthcare workers. An affordable paperless system would be an ideal way of dealing with this mode of SARSCoV-2 transmission.

\section{Background}

The national and provincial departments of health in South Africa have standing policies that regulate healthcare facility patient record keeping. Currently the majority of public healthcare facilities are using a paper-based record-keeping system. A goal in most provinces of SA is to migrate from a paper-based system to a paperless one. As anticipated, this is a slow process owing to the financial costs associated with such an upgrade.

Some tertiary healthcare facilities, such as Groote Schuur Hospital and Tygerberg Hospital (TBH) in Western Cape Province, have managed to achieve a partial paperless system. Inkosi Albert Luthuli Central Hospital in KwaZulu-Natal Province, a modern tertiary/ quaternary healthcare facility in operation since 2003, has a complete paperless system in operation. In some provinces, secondary and primary healthcare facilities have piloted a partial paperless recordkeeping system through the National Health Insurance (NHI) Health Patient Registration System (HPRS). Such a system has been successfully implemented in the Amajuba Health District in KwaZuluNatal, where the NHI programme has been piloted since 2012 .

There are many disadvantages associated with use of a paperbased patient record system, such as loss, duplication, theft, fire and research limitations. We are now faced with an additional disadvantage, which is transmission of the SARS-CoV-2 virus during handling of records. This practice can lead to an increase in the number of healthcare workers who test positive for the SARS-CoV-2 virus, with or without development of symptoms of COVID-19. An increase in the number of quarantined healthcare personnel, and in morbidity and mortality among healthcare workers, could potentially cripple the healthcare system.

\section{Discussion}

In the European Union and European Economic Area countries, most of which are developed countries with paperless electronic patient record systems, the burden of COVID-19 among healthcare workers was estimated to be $\sim 9-26 \% \cdot{ }^{[1-3]}$ This situation is still evolving in SA, since the peak of the disease curve has not yet been reached. As of 29 April 2020, nurses were found to be the most affected, accounting for $52 \%$ of all cases involving healthcare workers. At this time there were 195 reported cases of healthcare workers with COVID-19 in the private sector, and 133 in the public sector. ${ }^{[4]}$

The SARS-CoV-2 virus expelled by an infected individual has been found to survive for various lengths of time on different surfaces. It can live on cardboard or paper (e.g. patient record files) for 4 24 hours, ${ }^{[5]}$ a time window during which the SARS-CoV-2 virus can be transmitted. The virus may remain on smooth surfaces such as paper for longer than on non-smooth surfaces such as tissue paper. ${ }^{[6]}$

The Tygerberg Hospital COVID-19 response team has been using an application called Trello to monitor the COVID status of persons under investigation (PUIs) as SARS-CoV-2 reverse transcription polymerase chain reaction results become available, the transit and transfer of PUIs and confirmed COVID-19 patients from one hospital or ward to another, and numbers of admissions, deaths and 
discharges. The Trello app facilitates use of patient medical information without the physical manipulation of patient records. However, the patient record files were still kept in the wards with patients, and various healthcare personnel were manipulating the files for different reasons.

There are many medical apps designed to generate and contain patient medical histories and findings on examination and investigation. Most of these have transformed smartphones into convenient medical devices in patient care. They are governed by patient information privacy laws described upon subscription to each app. ${ }^{[7]}$ The Android and Apple apps of this type are passwordprotected, and examples used by clinicians in SA include Vula, Trello, Hospital Rounds Management, Rounds List and Dr. Rounds. Apps such as Trello can be used by multiple members of the same team, and a record of any changes made, and the details of the person applying changes, is kept.

A proposed algorithm that can be followed to achieve minimal manipulation of files during a patient's hospital stay, without violating the existing regulations in patient records management, is shown in Fig. 1. The process includes generation of a QR code for each patient admitted as a PUI or confirmed COVID-19 case. This code will be attached to the patient's cubicle at the door on single rooms, or on the patient's wristband or bedside, until discharge. During nursing rounds for medications, or doctors' rounds for patient review, a simple scan of the QR code will direct the clinician to the password-protected app with all the necessary information.

The patient's information will be kept on the app for the duration of his or her stay at the hospital. Upon discharge, a discharge summary will be drafted, and the inpatient clinical notes will be typed or printed according to the app used and filed as per provincial and/or institutional regulations. Healthcare workers will therefore have minimal exposure to the physical copy of the patient's medical records.

\section{Conclusions}

Further research is needed to determine the statistical significance of avoiding contact with physical copies of patients' records

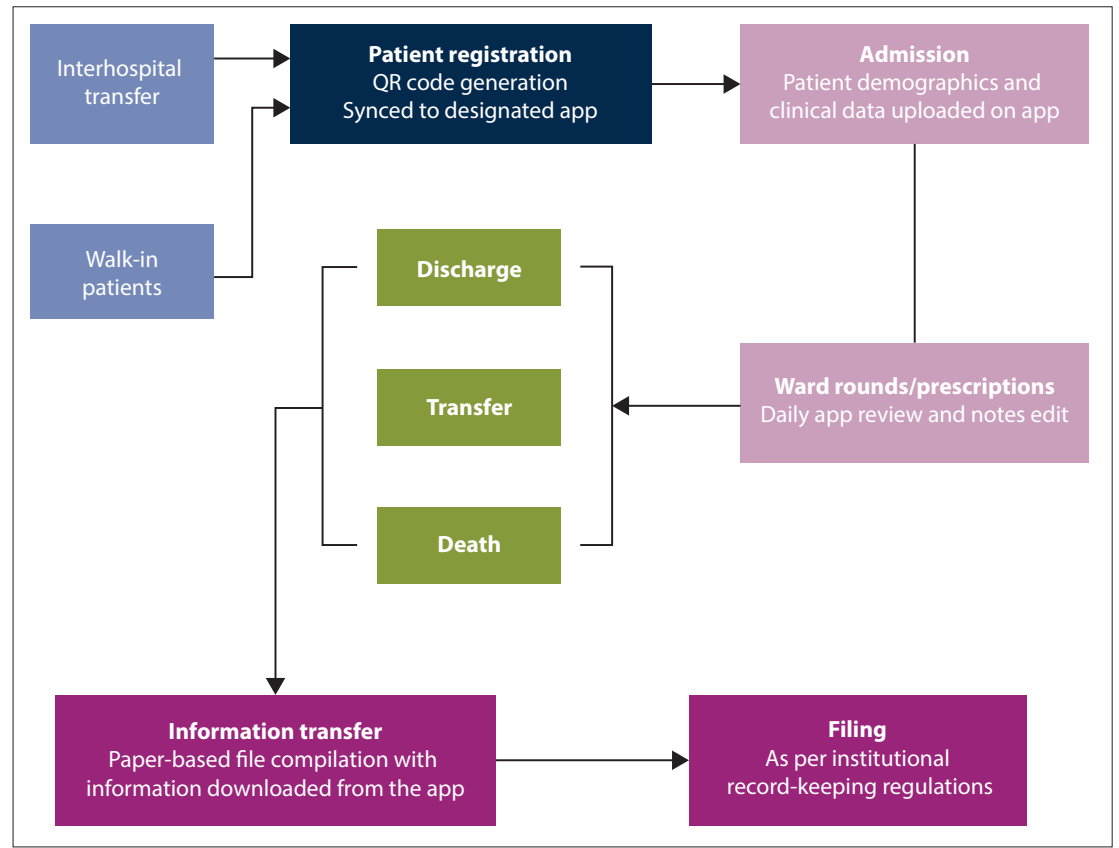

Fig. 1. Algorithm showing person under investigation/COVID-19 patient $Q R$ code - app - records process.

to reduce COVID-19 among healthcare workers. However, we have compelling evidence in recent literature that suggests an association between handling these records and the possibility of contracting COVID19. Alternative methods to avoid spread of COVID-19 among healthcare workers such as the one discussed should be explored.

\section{Learning points}

Spread of the SARS-CoV-2 virus among healthcare workers is a serious public health issue that should be addressed continually, with innovative measures put in place.

The use of modern technology such as medical apps on mobile devices could assist in reducing spread of the SARS-CoV-2 virus among healthcare workers.

Remember to safeguard the current regulations in patient care as innovative ideas arise and are implemented.

\section{Declaration. None.}

Acknowledgements. TBH COVID response team for experimenting with the Trello app.

Author contributions. SDN: concept, literature review, manuscript completion; $\mathrm{CM}$ : literature review, Fig. 1 design.
Funding. None.

Conflicts of interest. None.

1. Remuzzi A, Remuzzi G. COVID-19 and Italy: What next? Lancet 2020;395:1225-1228. https://doi.org/10.1016/S01406736(20)30627-9

2. International Council of Nurses. High proportion of healthcare workers with COVID-19 in Italy is a stark warning to the world: Protecting nurses and their colleagues must be to the world: Protecting nurses and their colleagues must be
the number one priority. https://www.icn.ch/news/highproportion-healthcare-workers-covid-19-italy-stark-warningworld-protecting-nurses-and (accessed 4 May 2020).

3. Ministerio de Sanidad Espana. Informe sobre la situación de COVID-19 en España. Informe COVID-19 no 20. 3 April 2020. https://www.isciii.es/QueHacemos/Servicios/ VigilanciaSaludPublicaRENAVE/EnfermedadesTransmisibles/ Paginas/InformesCOVID-19.aspx (accessed 4 May 2020).

4. Mlambo S. 328 health workers infected with Covid-19 in SA, Mlambo S. 328 health workers infected with Covid-19 in SA,
nurses hardest hit. Online IOL newspaper, 29 April 2020. https://www.iol.co.za/news/south-africa/328-health-workersinfected-with-covid-19-in-sa-nurses-hardest-hit-47326370

5. Doremalen NV, Morris DH, Holbrook MG, et al. Aerosol and surface stability of SARS-Cov-2 as compared to SARS-CoV-1. N Engl J Med 2020;382:1564-1567. https://doi.org/10.1056/ NEJMc2004973

6. Chin AWH, Chu JTS, Perera MRA, et al. Stability of SARSCoV-2 in different environmental conditions. Lancet Microbe 2020;1 (1):e10. https://doi.org/10.1016/s2666-5247(20)30003-3 7. Gan SK, Koshy C, Nguyen P, et al. An overview of clinically and healthcare related apps in Google and Apple app stores: Connecting patients, drugs, and clinicians. Sci Phone Appl Mob Devices 2016;2:8. https://doi.org/10.1186/s41070-016$0012-7$

Accepted 11 May 2020 (accessed 4 May 2020). 